\title{
CIÊNCIA, COGNIÇÃO E INFORMAÇÃO NA OPERACIONALIZAÇÃO DA GESTÃO PARTICIPATIVA DA ÁGUA NO BRASIL
}

\author{
Antônio Pereira Magalhães Jr.* \\ Oscar de Moraes Cordeiro Netto**
}

\begin{abstract}
Resumo: A aprovação da Lei da Água no Brasil (Lei nº 9.433/ 97) não garantiu a sua operacionalização, incluindo o princípio da gestão participativa nas instâncias dos organismos de bacia (Comitês de Bacia Hidrográfica). Este trabalho aborda a importância da consideração conjunta de conhecimentos científicos e vivenciais, bem como da organização de uma sociedade da informação em rede, para a viabilização deste processo. Aspectos como capacitação dos decisores, visão sistêmica, subjetividade, valores, percepções, atitudes, ética e diálogo são alguns dos elementos cognitivos abordados e considerados estratégicos para o sucesso da gestão participativa. O trabalho visa levantar reflexões sobre o papel do conhecimento e sobre a relevância da integração de qualidades individuais na busca de processos decisórios eficientes. A pesquisa foi realizada como parte do processo de doutoramento no Centro de Desenvolvimento Sustentável/UnB.

Palavras-chave: indicadores, comitês de bacia hidrográfica, gestão de águas.
\end{abstract}

\section{A recente abertura à gestão participativa da água no Brasil}

O termo gestão da água engloba, basicamente, três dimensões decisórias: o planejamento (formulação de princípios, diretrizes, planos de ação, regulamentos e políticas), a operacionalização de ações (ordenamento, controle e proteção da água, em termos de

\footnotetext{
* Professor do Departamento de Geografia, Instituto de Geociências da UFMG.

** Professor do Departamento de Engenharia Civil e Ambiental da UnB. Artigo recebido em 10 ago. 2003; aprovado em 21 set. 2003.
} 
disponibilidade e qualidade) e o monitoramento de resultados (acompanhamento e avaliação). Nesse processo, os decisores podem ser confrontados com a necessidade de compatibilização de usos e a resolução de conflitos de uso da água.

A gestão da água envolve um modelo de gerenciamento que estabeleça a organização legal/institucional e um sistema de gerenciamento reunindo os instrumentos para o preparo e execução das decisões. Entretanto, a definição de políticas e sistemas de gerenciamento da água não significa, obrigatoriamente, a obtenção de um modelo de gestão ideal. Entre os extremos de priorização da satisfação das necessidades humanas e priorização da preservação dos meios naturais, diferentes idéias e modelos de gestão surgiram, se modificaram ou desapareceram ao longo do tempo, em termos globais. A busca de equilíbrio e de adaptação às exigências nacionais exige, geralmente, mudanças nas relações e responsabilidades que envolvem o Estado e a Sociedade.

O processo de gestão participativa da água no Brasil foi, durante todo o século XX, atrasado pelo distanciamento da sociedade, por parte do poder público, do poder deliberativo nas instâncias de decisão. A tradicional priorização dos usos da água para geração de energia, irrigação e abastecimento de água potável, resultou em conhecidos problemas de poluição e saúde pública. As significativas necessidades atuais de investimentos em sistemas de coleta e tratamento de esgotos, bem como a degradação e artificialização dos ambientes aquáticos, ilustram essa lógica de gestão.

A degradação da qualidade da água, e sua escassez qualitativa e quantitativa estiveram associadas, historicamente, a modelos de desenvolvimento baseados na utilização irracional dos recursos naturais, no Brasil. A crise da água, no final do século XX, motivou reações e busca de soluções visando à compatibilização entre exploração econômica e utilização racional dos estoques ambientais. A partir dos anos 80, as iniciativas de modernização da gestão da água aproveitaram-se do "movimento" global de busca da sustentabilidade. Nessas circunstâncias, a gestão ambiental e a gestão da água tiveram sua importância reforçada nas políticas públicas de desenvolvimento de numerosos países, incluindo o Brasil. Esse processo de valorização e modernização da gestão da água permitiu 
e exigiu, entretanto, um maior envolvimento e participação da sociedade, fato que levou à soma de esforços para a conscientização social e à abertura aos princípios de gestão descentralizada e participativa. No início do século XXI, a gestão da água consolidouse como um dos elos mais eficientes de aproximação entre as esferas política, acadêmica e a sociedade civil.

As pressões nacionais e internacionais e o aumento da conscientização política, social e científica sobre a necessidade de busca de soluções para os problemas de degradação das águas, no Brasil, resultaram na aprovação da Lei no 9.433/97 (Lei da Água). Essa lei instituiu a Política Nacional de Recursos Hídricos (PNRH) e o Sistema Nacional de Gerenciamento de Recursos Hídricos (SNGRH), abrindo caminho para as novas bases da gestão participativa ancoradas no princípio da subsidiariedade. Dentre os componentes do SNGRH, destacam-se, para os fins deste trabalho, os Comitês de Bacia Hidrográfica (CBHs). Esses colegiados decisórios participativos são, atualmente, as mais importantes instâncias democráticas de gestão da água no país, em termos legais, congregando representantes de diversos setores da sociedade. Seu funcionamento envolve um "processo decisório" específico centrado na aprovação dos planos de gestão plurianuais das bacias e na definição e aprovação dos valores da cobrança pelo uso da água. Nos CBHs, os usuários e a sociedade civil têm, garantidos, o direito a, no mínimo, $40 \%$ e $20 \%$ dos votos, respectivamente. As Agências da Água, como organismos executores, são responsáveis, dentre outros, pela elaboração dos planos de gestão e de investimentos das bacias e pela aplicação do instrumento da cobrança pelo uso da água (Princípio UsuárioPagador).

O SNGRH é também constituído pelas organizações civis de recursos hídricos. A sociedade civil organizada (Terceiro Setor) compreende as Organizações da Sociedade Civil de Interesse Público (OSCIPS), definidas como pessoas jurídicas de direito privado (geralmente associações civis e fundações) sem fins lucrativos, voltadas à promoção e defesa de bens e valores da coletividade (Mantovani \& Barrêto, 2002). O Terceiro Setor, incluindo as Organizações Não-Governamentais (ONGs), firmou-se nos anos 90, dentre os principais vetores de contato entre o poder público e a 
sociedade civil, em termos globais. Porém, as ONGs também sofrem riscos de se profissionalizarem, de serem cooptadas por organismos organizados ou pelo poder público (dependência de recursos financeiros), de se burocratizarem e/ou de se centralizarem em alguns indivíduos em detrimento de uma democracia interna. Esses conflitos têm sido menos evidentes em ONGs ambientais locais (grassroots organizations), do que em ONGs sem suporte comunitário local (Bryant \& Bailey, 1997). Na busca de sua afirmação e do reforço de seu poder de decisão, todas as instâncias participativas passam atualmente pelo desafio da institucionalização da ação coletiva, exigindo o desvio do antagonismo histórico entre Estado e propriedade privada.

A atual fase de transição nacional é marcada pela multiplicação contínua de CBHs no país, mas o processo de operacionalização é lento e marcado por obstáculos conjunturais como a falta ou inadequação de dados para a gestão das bacias, a carência de recursos financeiros associada à falta de aplicação da cobrança, a falta de capacitação dos decisores, e o desequilíbrio de conhecimento técnico entre os membros decisores. Nesse último aspecto, os representantes da sociedade civil e do poder público local estão, geralmente, em desvantagem em relação aos representantes de instituições organizadas como as companhias de saneamento básico (Magalhães Jr., 2003).

Lambert (1996) ilustra a importância da necessidade de mudança dos modelos tradicionais de gestão da água no Globo, com base em princípios como a gestão participativa:

"surge hoje uma nova contradição no uso da água, entre natureza e sociedade. Contradição entre a coerência do ciclo hidrológico e a anarquia dos usos não compatíveis. A solução demanda uma nova lógica econômica, uma economia planificada, uma organização racional do espaço e das atividades, uma gestão democrática dos recursos. É, portanto, um problema de sociedade, um problema político" (Lambert, 1996).

A gestão da água exige, atualmente, uma nova forma de "governança", em que novos mecanismos de decisão sejam criados e novos atores entrem em cena (Meublat, 2001). 


\section{A governança como eixo norteador dos "novos rumos" da gestão da água no Brasil}

A crise da água tem sido associada à crise de governabilidade. A governabilidade da água envolve o conjunto de sistemas políticos, sociais e econômicos voltados ao desenvolvimento e manejo de recursos hídricos, e distribuição de serviços de água aos diferentes níveis da sociedade. Para ser efetiva, a governabilidade da água deve ser transparente, aberta, participativa, comunicativa, eqüitativa, coerente, integradora, ética e viável economicamente. Por seu lado, a governança é a forma como a sociedade participa do sistema de gestão (Peña \& Solanes, 2002).

O poder de participação resulta de uma conquista a partir de uma relação de forças construída com o poder político (pressão), ou como resposta à abertura política. A participação envolve diferentes formas de cogestão, incluindo os processos de geração e difusão de informações, opinião, concertação e decisão. O processo consultivo, no qual não é permitido aos cidadãos o poder deliberativo é, geralmente, realizado a partir de enquetes públicas de opinião ou de satisfação, estudos de impacto ambiental, reuniões públicas e conferências. Na concertação, é conferido aos cidadãos o poder de expertise, com o qual eles podem participar durante todo o processo decisório, em grupos ou comissões fixas, temporárias ou mesmo sob forma ad hoc. A capacitação dos decisores no processo de concertação tende a aumentar a capacidade e desempenho de intervenção. No processo de participação propriamente dito, há uma divisão eqüitativa de poderes entre os participantes, atingindo-se uma etapa de gestão conjunta baseada em co-decisões (Tab. 1). Nestas etapas, não obrigatoriamente sucessivas, é necessária atenção sobre os elementos que possam prejudicar a interatividade entre a oferta de participação (estruturas e processos da parte das autoridades) e a demanda de participação de setores da sociedade.

Duas metodologias têm sido propostas e utilizadas, internacionalmente, no sentido de potencializar os governos e as sociedades nacionais a transformar os modelos de desenvolvimento por meio da evolução das relações sociais e institucionais rumo à integração e à gestão participativa. A Comprehensive Development 
Framework (CDF) é uma abordagem ou um processo proposto pelo Banco Mundial, em 1999, que visa auxiliar os países a reduzir seus níveis de pobreza e desigualdades sociais a partir do foco da interdependência de todos os elementos do desenvolvimento (World Bank, 2003). A CDF está baseada em uma estratégia holística que se sustenta na motivação e capacitação dos próprios países a se autogerenciarem na busca do desenvolvimento sustentável e na efetivação da governabilidade e da governança, em termos racionais. Esta efetivação ocorre por meio de conscientização, forte cooperação/ integração entre setores da sociedade, incluindo os grupos marginalizados, para a busca do diálogo, troca de conhecimentos, consenso e redução da competição, bem como de transparência nos meios e resultados das iniciativas de desenvolvimento. A harmonização de estratégias operacionais, políticas e procedimentos, de todos os setores da sociedade, é vista como a mais importante prioridade na busca do desenvolvimento sustentável. O Banco Mundial salienta que cada país deve adaptar a CDF de acordo com seu contexto político, social, econômico e ambiental. Salienta, também, que todos os países do Globo enfrentam problemas e obstáculos para a implementação do processo, principalmente no que se refere à integração entre atores/gestores.

Outra abordagem que tem influenciado as políticas de desenvolvimento nacionais é a denominada SWAP - Sector Wide Approach -, também baseada na transformação das relações sociais rumo à cooperação e integração (RNG, 2003). A abordagem foi criada pelo governo da Holanda e tem sido aplicada na busca da redução da pobreza em países em desenvolvimento, ou subdesenvolvidos. A SWAP salienta a importância da capacitação nacional para o autogerenciamento e a existência de uma estrutura política consistente para a busca do desenvolvimento sustentável. Três noções básicas fazem parte da SWAP: gestão local integrada (participação popular), coerência no processo de gestão e coordenação racional. Considerando estas metodologias de busca de modelos de desenvolvimento mais racionais e associados a princípios de desenvolvimento sustentável, as experiências nacionais, inclusive no Brasil, não conseguiram, até hoje, obter os resultados esperados (Mario Diniz de Araújo Neto, professor do Departamento de Geografia/UnB, informação verbal, 2003). 
A falência do modelo secular de gestão da água no Brasil (centralizador e facilitador da hegemonia do setor energético) esteve associada à não aplicação efetiva de um sistema participativo, além de conhecidos problemas de carência de recursos humanos/financeiros e à falta de coordenação e integração institucional e informacional. Exemplos históricos ilustram que a associação de crises conjunturais têm sido o principal fator motivador de reformas nacionais, como a ocorrida no Brasil com a Lei $n^{\circ}$ 9.433/97 (Ménard, 2001): crise setorial (rarefação da água em quantidade e qualidade e baixo desempenho de gestão), problemas macro-econômicos (déficit público, dívidas, inflação), e modificação do poder político (fim do período das ditaduras militares no Brasil).

Tabela 1 - Processos participativos

\begin{tabular}{|c|c|c|c|c|c|}
\hline \multicolumn{3}{|c|}{ Tipos de Participação } & \multirow[b]{2}{*}{$\begin{array}{c}\text { Grau de } \\
\text { Participação }\end{array}$} & \multirow[b]{2}{*}{ Estruturas e Meios } & \multirow[b]{2}{*}{ Objetivo } \\
\hline $\begin{array}{c}\text { Nível de } \\
\text { relação e de } \\
\text { engajamento }\end{array}$ & $\begin{array}{l}\text { Momento de } \\
\text { intervenção }\end{array}$ & $\begin{array}{l}\text { Origem da } \\
\text { iniciativa }\end{array}$ & & & \\
\hline $\begin{array}{c}\text { Unilateral e } \\
\text { ativa }\end{array}$ & Curativa & Espontânea & Contestação & $\begin{array}{l}\text { Manifestação, } \\
\text { reinvidicação, } \\
\text { denúncia, alarmismo, } \\
\text { recursos judiciais. }\end{array}$ & $\begin{array}{l}\text { Retardar ou impedir } \\
\text { uma ação. }\end{array}$ \\
\hline \multirow{3}{*}{$\begin{array}{l}\text { Unilateral e } \\
\text { passiva }\end{array}$} & \multirow{3}{*}{ Preventiva } & \multirow{3}{*}{ Provocada } & Informação & $\begin{array}{l}\text { Publicações } \\
\text { obrigatórias, } \\
\text { procedimentos } \\
\text { formais. }\end{array}$ & $\begin{array}{l}\text { Pesquisa de } \\
\text { aceitação social ; } \\
\text { justificativas de } \\
\text { ação. }\end{array}$ \\
\hline & & & Educação & $\begin{array}{l}\text { Formação, } \\
\text { informação. }\end{array}$ & $\begin{array}{l}\text { Elevação do nível de } \\
\text { conhecimento ; } \\
\text { Esforços de } \\
\text { persuasão; } \\
\text { Modificação de } \\
\text { atitudes. }\end{array}$ \\
\hline & & & Comunicação & $\begin{array}{l}\text { Campanha de } \\
\text { sensibilização }\end{array}$ & $\begin{array}{l}\text { Conscientização de } \\
\text { problemas ; busca } \\
\text { de aceitação social. }\end{array}$ \\
\hline \multirow{4}{*}{$\begin{array}{l}\text { Bilateral e } \\
\text { ativa }\end{array}$} & \multirow{4}{*}{ Preventiva } & \multirow[t]{2}{*}{ Provocada } & Consultação & $\begin{array}{l}\text { Audições formais e } \\
\text { informais, } \\
\text { sondagens, } \\
\text { enquetes. }\end{array}$ & $\begin{array}{l}\text { Avaliação de } \\
\text { reações e opiniões; } \\
\text { definição de } \\
\text { necessidades. } \\
\end{array}$ \\
\hline & & & Concertação & $\begin{array}{l}\text { Debates, audições } \\
\text { públicas, grupos de } \\
\text { trabalho. }\end{array}$ & $\begin{array}{l}\text { Busca de soluções } \\
\text { consensuais. }\end{array}$ \\
\hline & & \multirow[b]{2}{*}{ Voluntária } & Co-decisão & $\begin{array}{l}\text { Referendum das } \\
\text { decisões. }\end{array}$ & Partilha de poderes. \\
\hline & & & Co-gestão & Organismo ad-hoc & $\begin{array}{l}\text { Planificação e } \\
\text { gestão conjunta ou } \\
\text { delegada }\end{array}$ \\
\hline
\end{tabular}

Fonte: Olivry (1985).

A valorização da gestão participativa não deve ocultar seus desafios e limitações quando não acompanhada de um real 
amadurecimento social para o processo de negociação. Dentre as reflexões e questionamentos necessários a tal amadurecimento, especificamente no Brasil, destacam-se:

\section{- A sociedade está preparada para a participação?}

Diversos fatores determinam o grau de interesse, iniciativa, dinamismo e consciência da sociedade em relação à gestão participativa, como o regime político e o nível socioeconômico da população. Esforços de conscientização e educação sobre os valores da cidadania e a importância do processo de participação, são essenciais à ruptura das forças de inércia e desmobilização.

- A sociedade está bem informada para exercer de forma competente a participação?

Não há gestão sem informação (sociedade da informação). Um dos principais condicionantes da gestão participativa é a acessibilidade dos decisores a informações adequadas.

- Os arranjos e interesses locais e setoriais em nível das instâncias participativas condicionam as decisões?

Sem uma certa homogeneidade do nível de conhecimento, as instâncias participativas correm o risco de se deformar sob os arranjos e interesses locais e setoriais determinantes das decisões. A tendência de ocorrência destes arranjos é inerente ao processo decisório, mas a democratização do conhecimento pode fazer prevalecer soluções de interesse comum.

- A gestão participativa é um fator de inovação ou um bloqueio à transformação?

A aceitação, por parte do Estado, da negociação de uma política, significa admitir que as decisões entre os interesses sociais divergentes serão arbitrados não mais pela autoridade política, mas pelos co-gestores. Porém, a gestão participativa não pode ser automaticamente associada à democratização do Estado ou à inovação. Os já mencionados riscos de desequilíbrio interno de forças podem determinar decisões pré-estabelecidas e comprometer o objetivo maior de defesa dos interesses comuns. Sem uma real 
participação embasada na liberdade e na capacidade de opinião e decisão, uma instância participativa pode apresentar uma certa continuidade de "vícios" do modelo de gestão não participativo, reforçando estruturas de poder locais.

As reflexões sobre tais questões e a busca de caminhos alternativos podem evitar a deformação do processo participativo, como mostram certas experiências de cogestão em outros países. Em realidades com maior tradição participativa, como a França, as discussões têm avançado sobre o questionamento da própria relevância do tradicional modelo participativo/representativo: a democracia representativa é o modelo de cogestão mais adequado, ou há condições de se concretizar uma democracia verdadeiramente participativa? Mesmo que a democracia representativa apresente os citados riscos de jogos de poder, ela é, por outro lado, o modelo mais pragmático. Uma grande abertura do processo decisório à sociedade, sem nenhum tipo de representação, corre o risco de transformá-lo em um processo estéril e improdutivo, tal a complexidade dos múltiplos interesses e opiniões mesmo no interior de uma classe ou de um setor socioeconômico. Para tal, o voto durante as eleições para representantes políticos é o melhor instrumento de participação universal. Os instrumentos de enquetes públicas, comissões consultivas e pesquisas de opinião são também instrumentos importantes que podem contribuir e auxiliar o processo decisório, fornecendo-lhe maior abrangência e aceitabilidade social.

Mesmo em países com tradição participativa, como a França, tem ocorrido uma intensificação de pressões sociais para uma maior abertura à participação social na gestão da água, fato muitas vezes motivado pela crise de confiança dos usuários em relação à qualidade e à transparência dos serviços públicos. As pressões sociais por mais transparência e qualidade dos serviços prestados têm motivado as companhias de saneamento a evoluir em suas relações com a sociedade, passando da tradicional referência do cidadão-usuário para a noção do cidadão-consumidor ou cliente. Nesse caso, os cidadãos deixam de ser vistos como atores passivos do sistema, para serem valorizados como atores responsáveis pela existência dos serviços e, portanto, com direito à informação e à opinião sobre o desempenho dos serviços. A antiga lógica de oferta de serviços cede espaço a uma 
lógica mais moderna de satisfação de demandas pelos gestores dos serviços públicos (Dubosc, 2001).

\section{As dimensões cognitiva e informacional como pilares da gestão participativa da água}

Um sistema decisório é comumente marcado por níveis hierarquizados (como o SNGRH), em que a primazia do nível superior está associada à redução das incertezas pelo nível inferior. A influência do nível inferior decorre de sua capacidade de resposta e de comunicação com os demais níveis do sistema. O constante fluxo de informações é essencial para o fluxo de deliberações e da validação da legitimidade da gestão participativa (subsidiariedade). Tem sido verificado que, apesar de mais lentos nas decisões, os grupos possuem maior probabilidade de acertos do que indivíduos isolados. Em grupos, os decisores tendem a se sentir motivados a acatar decisões das quais participaram. Por outro lado, grupos apresentam riscos de desequilíbrio de interesse, conhecimento, capacitação e poder de decisão, bem como desequilíbrio de sensibilidade e competência interpessoal. Esses empecilhos podem levar a interações ineficientes e manipulações de poder pelos decisores mais capacitados (ou por forças extragrupo), com base no condicionamento mental e comportamental interno (Hampton, 1991).

A gestão da água envolve uma seleção de um curso preferencial de ações a partir da escolha de alternativas. Neste processo, a disponibilidade e a qualidade das informações conferem maior confiabilidade e segurança. Muitas decisões são tomadas em um quadro de incertezas, principalmente em situações de escassez de informações. Os decisores e os processos decisórios podem ser diferenciados quanto ao uso da informação e ao foco das decisões. Em relação ao primeiro aspecto, uma das abordagens possíveis é a exaustividade, marcada pela contínua abertura na busca de informações até que se obtenha a solução desejada. A otimização do uso das informações e a aplicação do princípio da precaução são critérios potencialmente úteis nesse processo. $\mathrm{O}$ foco das decisões depende do número de alternativas para a tomada de decisões. Decisores unifocais preferem associar uma informação a uma solução 
ou curso de ação, correndo o risco de serem rígidos em suas decisões. Por outro lado, os decisores multifocais preferem associar uma informação a uma variedade de possíveis soluções alternativas, podendo levar a diversos cursos de ação simultâneos e a um processo mais flexível (Tab. 2). A definição de um problema está associada à ponderação entre uma definição funcional (o que o objeto faz), uma definição ontológica (o que o objeto é) e uma definição genética/ histórica (o que o objeto será).

\section{Tabela 2 - Tipos de decisores segundo o foco no uso das informações}

\begin{tabular}{c|c|c}
\hline Decisor & Características Positivas & Riscos \\
\hline Unifocal & $\begin{array}{c}\text { Imediata associação de uma solução ou um curso de } \\
\text { ação a um problema. } \\
\text { Idéias definidas sobre um problema. }\end{array}$ & $\begin{array}{c}\text { Rigidez excessiva } \\
\text { Inflexibilidade } \\
\text { Intransigência }\end{array}$ \\
\hline Multifocal & $\begin{array}{c}\text { Associação das informações a diversas soluções ou } \\
\text { diferentes alternativas para o problema. } \\
\text { Flexibilidade e abertura de idéias; argumentação. }\end{array}$ & $\begin{array}{c}\text { Falta de } \\
\text { objetividade/praticidade } \\
\text { Falta de clareza }\end{array}$ \\
\hline
\end{tabular}

Fonte: Adaptado de Driver, Brousseau \& Hunsaker, 1993.

A tomada de decisões está inserida em um contexto de riscos e incertezas, envolvendo probabilidades associadas a múltiplas alternativas ou fatos desconhecidos. Decisões programadas (problemas rotineiros e conhecidos para os quais é possível estabelecer um procedimento-padrão), envolvem maior grau de certeza do que decisões não programadas (Szilagyi Jr, 1984). Em um quadro de carência de informações confiáveis, os decisores tendem a atuar sob condições predominantes de incertezas, justificando a necessidade de programas de monitoramento que permitam a geração contínua de dados e o aprimoramento das bases existentes (rede informacional). Porém, mesmo os avanços na disponibilização de informações de qualidade não têm sido capazes de evitar, especificamente a partir dos anos 90, situações de incerteza no mundo. Como resultado, surgem, por exemplo, "crises" financeiras motivadas por fatores como guerras, mudanças de governos ou mesmo epidemias. Apesar da recente e acelerada evolução tecnológica nos processos de geração/ transmissão/tratamento de informações, situações de incerteza e de riscos continuam a determinar os comportamentos humanos e as políticas econômicas e de desenvolvimento. 
Em um processo decisório, a identificação do problema é seguida por sua análise e busca de soluções. Sob esse aspecto, quatro estilos de decisores podem ser identificados: "perceptivo" (prioriza as informações mais adequadas), "receptivo" (considera qualquer informação recebida), "sistemático" (apóiam-se em estruturas metodológicas) e "intuitivo" (não se baseia em conhecimentos científicos). Esse último estilo envolve aspectos cognitivos associados à vivência e à percepção do decisor. Na etapa de escolha da alternativa adequada, a tendência de aceitação da primeira impressão de um problema, restringe o processo de decisão. A carência de informações também limita a escolha, assim como o fato das escolhas derivarem de um ato de julgamento que envolve valores pessoais (subjetividade). Geralmente, a etapa de escolha de alternativas e soluções é seguida pelas etapas de implementação das decisões e de avaliação dos resultados (desempenho). Nesse aspecto, tornam-se pertinentes pelo menos três questões: Em que proporção as metas foram atingidas (eficiência)? Qual o grau de comprometimento dos envolvidos nas decisões de curto, médio e longo prazo? Outras decisões poderiam ter sido tomadas? Há uma diferença acentuada entre decisões ideais e decisões operacionais. Sob condições de falta de informação, o decisor pode transformar idéias em suposições ou tolerar as ambigüidades e os dados incompletos. O processo decisório é, portanto, um sistema caracterizado pela escolha de cursos de ação entre alternativas, no qual os planos iniciais devem ser aprimorados até a obtenção do plano final.

No processo decisório participativo, os decisores devem ser potencializados e capacitados, munidos de informações, qualificações e atitudes adequadas para decidir. Um dos pilares da governança é a plena compreensão das funções e metas de trabalho (Fig. 1). A capacitação está associada à compreensão das respectivas responsabilidades e funções, bem como da razão das metas e objetivos. Um dos fatores de desmotivação em um grupo decisório é a sensação de não contribuição, resultado, dentre outros, da falta de esclarecimento. A motivação resulta, também, de um sentido de orgulho pessoal, um catalisador que leva as pessoas a descobrirem e utilizarem o seu poder pessoal. O orgulho individual deriva em grande parte do sentido de responsabilidade e do reconhecimento do papel do decisor. 
A operacionalização da governança depende de autoridade dos decisores para exercer suas funções. Autoridade implica liberdade de idéias e de ação, sem obstáculos legais, institucionais ou ideológicos. Os decisores também devem estar conscientes da necessidade de informações, para que possam demandá-las ou gerálas, em uma lógica de consumo e de produção de conhecimento.

\section{Figura 1 - Pilares da Governança}

\begin{tabular}{|c|c|}
$\substack{\text { Confiança } \\
\text { autoconfiança }}$ & Reconhecimento/ Valorização de resultados \\
Intercâmbio informacional (sociedade em rede) & Esclarecimento de objetivos e metas \\
Delegação de autoridade: subsidiariedade \\
Capacitação/Informação/Motivação \\
Esclarecimento/valorização de responsabilidades
\end{tabular}

Liberdade de expressão e ação

Fonte: Adaptado de Tracy, 1994.

Respeito

Todo processo de gestão implica tomada de decisões, individual ou coletivamente. As decisões são tomadas, por sua vez, com base no conhecimento científico ${ }^{1}$ ou com base no conhecimento obtido por meio das experiências e percepções humanas. Porém, o conhecimento empírico também pode ser interpretado como conhecimento científico, já que resulta dos processos conjuntos de observação e classificação dos fenômenos, seguidos da elaboração de idéias ou princípios gerais (Williams, 1999). Portanto, qualquer processo de organização de idéias derivado da observação direta dos fenômenos e, com o tempo, da experiência física e sensorial, estaria associado ao conhecimento científico. Nesse sentido, Williams ilustra que os homens préhistóricos, os egípcios e outras civilizações antigas aplicaram, de forma prática, o conhecimento científico (ciência antiga), e não foram menos lógicos do que o homem moderno nesse processo. Nesse caso, o homem aplicava o conhecimento científico, mas não o formulava, ou seja, a diferenciação refere-se apenas ao grau e não no tipo de conhecimento.

A história da epistemologia demonstra, no entanto, que a natureza do conhecimento nunca foi um tema consensual (Gardner, 1995). O início do seu estudo é atribuído a Platão (429-347 a.C.), 
cuja teoria baseava-se na explicação do conhecimento como produto da posse inata das idéias das ciências exatas. Somente o aprendizado permitiria, segundo Platão, que o homem adquirisse as reminiscências do conhecimento que é inerente à alma humana (teoria da reminiscência das idéias). Na mesma época, Aristóteles desenvolveu sua teoria do conhecimento, concordando em parte com Platão, mas aceitando que a realidade material também influencia a aquisição de conhecimentos. A escola de Aristóteles influenciou as discussões sobre a natureza do conhecimento durante toda a Idade Média, mas, após o Renascimento, o tema começou a ser tratado com base nos primeiros resultados das ciências empíricas. Assim, Francis Bacon (1561-1626), René Descartes (1596-1650), John Locke (1632-1704), Gottfried Leibnitz (1646-1716), David Hume (1711-1776) e Immanuel Kant (1724-1804) tentaram conciliar a pesquisa teórica com as experiências empíricas relativas ao espírito humano. Bacon também rompeu com as idéias de Aristóteles, não concordando com a afirmação de que "tudo o que existe na natureza é inato, e não pode ser modificado pela experiência". Ao analisar a mudança dos fatos a partir do método indutivo, Bacon contribuiu com a fundação da ciência moderna.

Descartes defendeu os princípios do racionalismo e da evidência, segundo os quais a mente humana é a única capaz de explicar o que é verdadeiro por meio da comprovação dos fatos. Seus princípios valorizaram a importância da dúvida e da aceitação apenas do que possa ser estritamente provado. Para Descartes, as idéias reais têm causas inatas e não empíricas, mas somente o próprio ser pensante pode fundamentar a comprovação dos fatos. A mente racional é indivisível e separada do corpo material (concebido como uma "máquina"). Já as experiências (conhecimento empírico) seriam responsáveis por erros e imperfeições humanas.

As idéias de Descartes foram contestadas por empiristas como Thomas Hobbes, John Locke, George Berkeley e David Hume (Gardner, 1995). Locke criticou a existência de idéias inatas, argumentando que a experiência seria a única fonte de conhecimento possível. Para Berkeley, o homem produziria abstrações e generalizações com a interação das idéias obtidas a partir da experiência. Os fatos materiais, as sensações e as idéias somente existiriam quando percebidas por um ser pensante. A compreensão 
dos fatos passaria, então, pela percepção do sujeito e, conseqüentemente, por sua experiência. Por seu lado, Hume criticou o princípio da causalidade do cartesianismo (causa-efeito), propondo que somente a experiência e o hábito explicariam a repetição de fatos em momentos distintos. Todo o pensamento humano derivaria, então, das sensações internas e externas.

Em meio a confrontos entre os racionalistas/cartesianistas, para os quais o pensamento é o responsável pela organização e revelação do conhecimento, e os empiristas, para os quais o pensamento é o instrumento de reflexão ou elaboração da experiência física, Kant propôs uma análise mais crítica da razão. Para ele, a mente seria responsável por moldar e organizar as sensações e idéias resultantes da experiência, transformando-as em um pensamento estruturado. $\mathrm{O}$ conhecimento seria resultante, portanto, da organização da experiência sensorial do ambiente em categorias de pensamento, e não de imagens dos objetos ou de intuição pessoal. Kant descartou a validade de uma psicologia empírica, alegando que a mente não é capaz de conhecerse a si mesma como objeto de experiências espaciais e temporais. Este pressuposto representaria um obstáculo à futura ciência cognitiva.

No final do século XIX, diferentes disciplinas discutiam e pesquisavam a natureza da mente humana de acordo com seus próprios métodos, mas evoluíam principalmente a partir de especulações abstratas típicas do método científico introspectivo da época. $\mathrm{O}$ "behaviorismo" (estudo do comportamento humano dominante entre os anos 20 e 40) adotou, no início do século XX, um programa de observações empíricas do comportamento humano que visou, dentre outros, a combater as especulações subjetivas. Quaisquer idéias de cunho mentalista, relacionadas a sentimentos, crenças, imaginações e desejos eram taxadas como não científicas. $\mathrm{O}$ behaviorismo se baseava no modelo mecanicista do arco-reflexo, segundo o qual os comportamentos humanos são avaliados pela fórmula estímulo resposta (input-output).

$\mathrm{O}$ estudo da mente humana permaneceu sem um referencial investigativo na primeira metade do século $\mathrm{XX}$, impedindo a constituição de uma disciplina cognitiva cientificamente estruturada. A partir dos anos 40, diferentes pesquisadores começaram a questionar 
o paradigma comportamental, demonstrando que comportamentos seriais e ordenados não podem ser explicados apenas em função de estímulos e respostas. Para Karl Lashley (citado por Gardner, 1995), as ações humanas possuem um planejamento prévio que decorre do conhecimento organizado no interior do organismo. Este conhecimento interior determinaria o comportamento, e não o conhecimento exterior, como apregoavam os behavioristas.

Beneficiando-se da evolução da informática no pós-guerra, estudiosos como Alan Mathison Turing, John von Neumann, Norbert Wiener, Kenneth Craik e Alexander Romanovich Luria retomaram as teorias do comportamento e da mente humana que haviam sido abafadas pelo behaviorismo, formando as bases da ciência cognitiva nos anos 50. A ciência cognitiva foi reconhecida a partir dos anos 70, possuindo destacada atuação de disciplinas como filosofia, psicologia, lingüística, antropologia e neurologia. $\mathrm{O}$ estudo das questões cognitivas envolve a maneira como o homem concebe o mundo e a si próprio, o entendimento da mente humana e do conhecimento empírico resultante da realidade humana. Em síntese, busca-se estudar o que é passível de ser conhecido, as características de quem está capacitado a conhecer, as fontes do conhecimento e as dificuldades de sua obtenção e manutenção.

Os aspectos cognitivos explicam, em parte, as atitudes humanas. Os indivíduos organizam os componentes afetivos (sentimentos) e cognitivos (crenças) em um sistema de atitudes que resulta em comportamentos (respostas). Aspecto importante desta evolução nos estudos comportamentais é o reconhecimento que os avanços da ciência cognitiva dependem de definições operacionais, de interrelações entre comportamentos verbais e operacionais, de mensuração de processos e de estruturação de paradigmas (Mitchell, 1979). As atitudes condicionam as decisões humanas em termos das opiniões pessoais dos decisores, das opiniões dos decisores sobre as preferências alheias, e, finalmente, das opiniões dos decisores sobre quais devem ser as preferências alheias.

Pesquisas de opinião de Sewell's nos EUA (1971 citado por Mitchell, 1979) ilustram a importância da percepção e das atitudes na formação de opiniões e na abertura à gestão participativa. $\mathrm{O}$ autor 
concluiu que, em geral, os especialistas se comportam como fazendo parte de "sistemas fechados" fortemente atrelados às respectivas formações profissionais ("doutrinação profissional"). Essa posição está associada ao pressuposto, geralmente presente, de que não há a necessidade de intercâmbio de idéias com outros profissionais ou com a sociedade civil, em geral. Esse fato se torna grave sabendo-se que, como o próprio autor salienta, "os decisores e o público, em geral, têm, freqüentemente, diferentes e conflitantes opiniões sobre políticas e práticas de gestão".

A informação ocupa uma posição central em todo o processo cognitivo, fato formalizado nos anos 30 pelo matemático norteamericano Claude Elwood Shannon, quando defendeu que a informação independe do meio de transmissão e pode ser estudada em qualquer mecanismo transmissor. A evolução da ciência cognitiva motivou o desenvolvimento dos estudos de "percepção ambiental". Um de seus pressupostos básicos é que como a percepção é governada pelas experiências passadas e pelo conhecimento atual do indivíduo ou de coletividades, envolvendo valores, circunstâncias sociais e expectativas, dois indivíduos que recebam os mesmos estímulos podem ver diferentes imagens (Mitchell, 1979). Segundo Jung, "a grande decisão da vida humana tem uma norma muito mais relacionada com... fatores inconscientes do que com desejos conscientes e racionais" (Hampton, 1991).

Consciente ou não, um decisor pode estar fortemente disposto a certa alternativa, mas o que ele exprime como justificativa para suas escolhas pode ser uma racionalização. Mitchell (1979) salienta a incoerência entre o que expressamos verbalmente e o que fazemos ou acreditamos realmente. A Teoria da Dissonância Cognitiva busca explicar que os indivíduos podem não ser consistentes quanto à conformidade entre suas cognições internas e suas cognições comportamentais, levando-se em conta sua experiência. Os indivíduos que parecem atuar irracionalmente, nesse caso, estão, de fato, atuando de forma consistente com um padrão resultante da dissonância cognitiva.

Ainda no campo das questões cognitivas, a Teoria da Ação Racional (TAR), defendida por Kant e atualmente bem conhecida 
das ciências sociais, econômicas e políticas, salienta que as escolhas dos atores racionais são sempre guiadas por suas preferências pessoais em termos de relação custo-benefício (Gleason, 2003). Nesta ótica, nem sempre o que dizemos ou pensamos condiz com o que fazemos. Quando o homem atua visando atingir metas estabelecidas, sua ação é considerada racional. A ação racional visa estabelecer uma correlação entre meios e metas. Os atores racionais são vistos como unidades decisórias individuais ou coletivas com objetivos e estratégias comuns, e cujas escolhas e valores maximizam os resultados (como, por exemplo, o valor de um bem ou serviço). As estratégias são, justamente, os planos de ação que determinam os meios para a obtenção das metas intentadas. A TAR não defende que os atores racionais façam sempre escolhas "corretas", pois eles podem, deliberadamente, fazer escolhas determinadas pela emoção ou utilizar informações inadequadas. Um ator coletivo pode estar, também, internamente dividido, tornando difícil o consenso. Por meio da ação racional, a sociedade pode colocar em prática, meios de cooperação e integração, mas a ação racional pode ser executada por motivações de interesses comuns ou devido a obrigações (ação forçada). $\mathrm{Na}$ realidade, a TAR salienta que a cooperação é sempre permeada por interesses paralelos que mesmo beneficiando as partes envolvidas, o fazem desigualmente envolvendo processos como a coerção e a extorsão. Este rompimento na cadeia de cooperação resulta em comportamentos "deformados", como a dissimulação e a representação. Modernos teóricos políticos salientam que a cooperação é determinada por fatores como liderança, gestão, estilo organizacional, monitoramento, avaliação e a relação entre ação e resultados, mas, acima de tudo, pelo reconhecimento da importância da ação coletiva na resolução de problemas comuns. As emoções e os valores pessoais estariam subjacentes às escolhas, visando um objetivo dito "racional", sob esta ótica.

Uma das principais críticas feitas à TAR é a dificuldade de mensuração e verificação das preferências e valores humanos. Segundo a Teoria da Escolha Racional (TER), defendida por Elster (1989; citado por Varese, 2001), uma escolha satisfaz três condições ótimas: os atores possuem preferências ou desejos que não podem ser classificados como racionais ou irracionais, o curso de ação escolhido será o meio de colocar em prática as preferências e valores do decisor, 
e, finalmente, as ações escolhidas visam otimizar os resultados esperados, considerando as informações disponíveis. Neste caso, a quantidade e a qualidade das informações disponíveis devem ser ótimas, considerando os custos e benefícios da aquisição de informações em relação aos resultados esperados.

Uma das abordagens dominantes nas ciências cognitivas é a IPA (Information Processing Approach), sendo baseada no pressuposto de que o sistema cognitivo e o meio ambiente são externos e independentes um do outro. Isto significa que as habilidades humanas em manipular, interpretar e armazenar informações são independentes e co-existem em relações causais. A IPA está associada à noção de IRN (Inter-Representation Networks), proposta por Portugali (1996), a qual também pressupõe que os elementos que compõem o ambiente, incluindo sistemas de informações, constituem representações externas do sistema cognitivo. A IRN propõe importantes pressupostos cognitivos (Portugali, 2002):

- a mente humana (representações internas) e o ambiente humano (representações externas) são relativamente independentes um do outro, e sua interação constitui os sistemas cognitivos;

- as representações externas resultam da relação entre aspectos cognitivos individuais e coletivos;

- o sistema cognitivo é um sistema auto-organizado.

A noção de IRN está implícita nas idéias de "mapeamento cognitivo" de Tollman, para o qual o mapa cognitivo é uma representação interna inserida na estrutura comportamental representada externamente. Também está associada às idéias de Lynch (citado por Portugali, 1998) sobre os elementos básicos das representações externas com as quais construímos as imagens da cidade (representações internas). São eles: vias de circulação, áreas, junções, cruzamentos e marcos espaciais de referência.

A construção do conceito de IRN foi inspirada na "abordagem sinérgica da auto-organização", de Haken, baseada na estrutura neural do cérebro humano, bem como nas idéias de David Bohm, 
especificamente a denominada "Bohm's philosophy of implicate and explicate order" (Bohm, 1992). Bohm ficou conhecido por suas teorias holísticas aplicadas à física quântica, e por suas críticas à "falta de criatividade da física moderna". Uma de suas obras mais conhecidas é A totalidade e a ordem implicada: uma nova percepção da realidade (Bohm, 1992), na qual o autor propõe a teoria holonômica (oposta à perspectiva hierárquica) apoiada no princípio de que toda parte do Universo é um testemunho da sua estrutura e processo evolutivo (o todo está contido na parte). ${ }^{2} \mathrm{Na}$ ordem implícita, o espaçotempo não é o fator determinante das relações de dependência dos elementos do espaço, enquanto na ordem explícita, surgem nossas noções ordinárias de espaço-tempo e a existência de partículas materiais independentes resultantes das abstrações internas.

A partir da noção de IRN, Haken e Portugali (1996) propuseram a denominada SIRN (Synergetic Inter-Representation Networks), considerando os pressupostos sinérgicos da auto-organização de Haken. Uma SIRN seria uma rede baseada em processos e mapas cognitivos vistos como o produto de uma rede sinérgica autoorganizada formada por representações internas e externas interligadas. A SIRN pressupõe que os limites do sistema cognitivo são distintos dos limites entre cérebro e corpo humano e a cognição é vista como um mecanismo de processamento de informação, assim como um processo de transmissão e comunicação de informação. As representações externas seriam potenciais "deformadoras" de informações. Os autores propõem a busca de um meio de representação (interna e/ou externa) que seja apropriado para cada situação. O "Variable Cultural Code" é proposto como um meio de interligar as redes neurais e as representações externas, definindo cada sistema cognitivo individual e cada representação por meio de um código cultural remanescente de um código genético.

As redes de informações foram estudadas por Castells (1999), para o qual a tecnologia e a informação são a base de transformação da humanidade e das estruturas sociais. A revolução tecnológica global das últimas décadas, associada às transformações na capacidade e nos métodos de geração, transmissão e tratamento de informações, constituiria a essência da denominada sociedade da informação (sociedade em rede). Para o autor, o Estado é o responsável pela 
revolução da informação em todo o mundo e o aprimoramento individual é a chave para o sucesso desta nova sociedade na qual a tecnologia deve continuar evoluindo sem prejudicar a qualidade de vida e o bem-estar humano. Por outro lado, a sociedade informacional é marcada pela recepção dos impactos das informações produzidas na sociedade da informação. Castells (1999) destaca que qualquer alteração nos instrumentos e meios de transmissão de informações (fluxo), gera importantes transformações sociais e psicológicas na humanidade.

A gestão da água envolve a formulação de políticas e planos de ação e a aplicação de decisões. Esse processo é permeado por valores humanos que definem escolhas e critérios de decisão e envolvem um conjunto de condicionantes sociais e motivações que governam o comportamento humano. Os valores humanos determinam, em grande parte, a valoração de um recurso em função de seus diferentes usos: Valor de uso (valor derivado do uso do recurso), Valor de opção de uso (valor derivado do uso potencial do recurso), Valor de existência (valor baseado em uma situação de não uso do recurso) e Valor intrínseco, esse último estabelecido por motivações éticas e morais associadas à existência do recurso.

As recentes discussões sobre a necessidade da "modernização" dos modelos de gestão da água, no globo, estão, portanto, associadas a questões cognitivas e subjetivas que podem comprometer um processo decisório, se não consideradas. Um exemplo decorre da noção de qualidade de vida, a qual está intrinsecamente relacionada à gestão da água. A qualidade de vida pode ser entendida como a soma das condições econômicas, ambientais, científico-culturais e políticas coletivamente construídas e postas à disposição dos indivíduos para que possam realizar suas potencialidades (Herculano, 1998). Ela inclui a acessibilidade à produção e ao consumo, aos meios para produzir cultura, ciência e arte, bem como pressupõe a existência de mecanismos de comunicação, de informação, de participação e de influência nos destinos coletivos. A avaliação dos benefícios para a coletividade resultantes da utilização da água deve ter em conta as várias componentes da qualidade de vida, incluindo a qualidade ambiental. 
Uma das dificuldades do estudo da qualidade de vida é a sua subjetividade e a falta de consenso conceitual, já que envolve fatores cognitivos individuais. $\mathrm{O}$ homem julga a qualidade de vida à medida em que o mundo que o cerca corresponde às suas expectativas e necessidades: equilíbrio ambiental, interação social, conhecimento, etc (Moles, 1995). As diferenças entre nível de vida e qualidade de vida são baseadas, sobretudo nos tipos de necessidades atendidas, mas ambos envolvem a noção de "satisfação" (Tab. 3). O nível de vida está associado diretamente à posse de bens materiais que proporcionam satisfação pessoal e conforto. Já a qualidade de vida envolve, além da posse de bens materiais, questões cognitivas relacionadas a sentimentos, percepções e valores que proporcionam satisfação pessoal.

A melhoria da qualidade de vida está associada aos princípios essenciais do desenvolvimento sustentável: integridade ecológica, crescimento econômico e ética comportamental (Correia, 1999). A integração desses princípios pode permitir a repartição, de forma socialmente equânime, dos custos e benefícios das intervenções humanas no meio ambiente (externalidades ambientais). A noção de gestão sustentável da água, disseminada nos anos 90, está ligada ao objetivo de universalização do acesso contínuo à água. Em nível decisional, o desenvolvimento sustentável exige a consideração de questões como a irreversibilidade e a incerteza potenciais das decisões (princípio da precaução), a pluralidade de pensamentos e a interdisciplinaridade (IFEN, 1999). O combate à pobreza tem sido apresentado como um dos pilares das políticas de gestão sustentável da água, devido à sua forte associação à degradação dos estoques naturais.

\section{Tabela 3 - Bem-estar/Satisfação e Nível de Vida/Qualidade de Vida}

\begin{tabular}{l|l|l}
\hline \multicolumn{1}{c|}{ Categoria } & \multicolumn{1}{c}{ Bem-estar } & \multicolumn{1}{c}{ Satisfação } \\
\hline $\begin{array}{l}\text { Nível de } \\
\text { vida }\end{array}$ & $\begin{array}{l}\text { A satisfação depende da posse de bens } \\
\text { materiais: "ter". }\end{array}$ & $\begin{array}{l}\text { Satisfação individual em } \\
\text { relação às condições de } \\
\text { vida materiais. }\end{array}$ \\
\hline $\begin{array}{l}\text { Qualidade } \\
\text { de Vida }\end{array}$ & $\begin{array}{l}\text { A satisfação engloba a posse de bens materiais } \\
\text { e fatores cognitivos (percepções, valores, } \\
\text { sentimentos, relações sociais): "ter", "amar", } \\
\text { "estar", "ser". }\end{array}$ & $\begin{array}{l}\text { Satisfação individual em } \\
\text { relação à satisfação de } \\
\text { necessidades materiais e } \\
\text { imateriais. }\end{array}$ \\
\hline
\end{tabular}

Fonte: Adaptado de Horn (1993). 
$\mathrm{O}$ aumento contínuo da oferta hídrica, em qualidade e quantidade (o tradicional modelo de gestão vigente no século XX em acordo com o modelo econômico keynesiano), mostrou suas limitações quanto à sua incapacidade de evitar a exploração irracional da água, no globo. A partir dos anos 80, a valorização do "paradigma" da regulação da demanda da água esteve associada às idéias sobre desenvolvimento sustentável que se disseminaram após a II Conferência das Nações Unidas sobre Meio Ambiente e Desenvolvimento, em 1992. Desde então, têm se tornado comuns as idéias de busca da sustentabilidade do uso da água a partir da gestão racional da demanda por meio de instrumentos regulamentares, participativos e econômicos.

A utilização de instrumentos econômicos ilustra claramente os desafios associados à incorporação de aspectos subjetivos e éticos na gestão da água. Essa utilização tem se ancorado no argumento de que o mercado de livre iniciativa não é, por si só, eficiente para a promoção do uso socialmente ótimo do ambiente. A cobrança tem sido o principal instrumento econômico adotado nas modernas abordagens de gestão da água, a qual visa racionalizar o uso da água e arrecadar receitas para os investimentos necessários à conservação e à recuperação da qualidade e da disponibilidade hídrica. A cobrança envolve o pagamento pelos volumes utilizados (objetivo de controle da demanda e do desperdício) e pela poluição da água (controle dos volumes de efluentes gerados). Esse instrumento já era aplicado na década de 1930 na bacia do rio Ruhr (Alemanha), disseminou-se no final dos anos 60 na Holanda e na França (redevances), e é atualmente adotado em diversos países do Globo, incluindo o Brasil. Aplicada de forma adequada, com valores justos e éticos, a cobrança pode combinar a exigência de eficácia (internalização de externalidades) e de eqüidade na imputação de custos aos poluidores (Bursztyn, 1994). Desta forma, podem-se mudar padrões e comportamentos sociais, promover a eficiência econômica da utilização do recurso, internalizar custos externos e levar a sociedade a exigir serviços de melhor qualidade e maior eficiência (Cosgrove \& Rijsberman, 2000).

A valorização da água como recurso econômico é um fenômeno relativamente novo em escala mundial. Há cerca de 150 anos, JeanBaptiste Say, um dos pais da economia ocidental, afirmava que "as 
riquezas naturais são inesgotáveis, e não podendo ser multiplicadas ou esgotadas, não constituem objeto das ciências econômicas" (Bellia, 1996). Por volta de 1920, a consideração da água como bem econômico beneficiou-se do princípio das externalidades, proposto por Pigou, cuja essência apóia-se na idéia de que o meio ambiente é um patrimônio coletivo, e a maximização das satisfações individuais pode levar ao repasse dos custos externos à sociedade. As externalidades negativas (deseconomias externas), resultariam da desconsideração, pelo mercado, dos danos que o processo produtivo gera a terceiros. Esses danos podem ser relativos à perda do bemestar de outrem e são custos sociais não compensados (Bursztyn, Benakouche \& Bursztyn, 1994).

A cobrança apresenta, além de vantagens, inúmeros desafios, um dos quais é o caráter subjetivo da valoração dos recursos hídricos. Tal subjetividade envolve vivências e percepções sociais sobre o valor da água, incluindo o valor intrínseco estabelecido por motivações éticas e morais, temática abordada por autores como Reid (1962), Lovelock (1979), Goldblatt (1996) e Diegues (1996). Mesmo com a existência de algumas técnicas de valoração ambiental, como a técnica de disposição a pagar (disposição do cidadão em pagar pelo uso de dado recurso ou serviço ambiental), o tema suscita mais controvérsias do que consensos.

\section{Diálogo e visão sistêmica no processo decisório participativo}

O processo decisório participativo envolve conhecimentos científicos e vivenciais. Apesar da importância desses últimos, originados da experiência local, cabe a consideração dos riscos de generalizações intuitivas na gestão participativa. Um dos instrumentos de minimização desses riscos é a instauração de um sistema de diálogo como elo de integração de conhecimentos. Nesse sentido, Bohm (1998 citado por Mariotti, 2003) sugeriu que cada operação mental requer a utilização integral do todo conhecido, incluindo informações intuitivas, sentimentos e imagens (integração). Estas idéias seriam importantes não apenas para a formulação de teorias, mas também para a busca de harmonia e estabilidade nas relações humanas a partir da compreensão da mente. Com a evolução de seus estudos, Bohm 
concluiu que diferentes formas de diálogo, e não de discussão, podem ser um dos mais efetivos meios de investigação sobre a natureza e a consciência humana e sobre a crise pela qual passa a sociedade humana. A discussão ordinária, marcada por posições pessoais e idéias fixas e pela tentativa de convencimento dos demais, pode produzir, no máximo, concordância ou acordo, mas não leva a nenhuma liberação de criatividade, segundo o autor. As frustrações trazem raiva e ódio, enquanto a livre troca de idéias e informações seria um meio eficiente de liberação de criatividade, de transformação cultural e de capacitação.

Ainda considerando a importância das questões cognitivas na gestão participativa da água, Mariotti (2003) concebe o diálogo, a partir da origem etimológica da palavra ${ }^{3}$ como uma metodologia de conversação que busca melhorar a comunicação entre os interlocutores, compartilhar experiências e gerar percepções e idéias novas. Enquanto a discussão e o debate são interações verbais que busca gerar sínteses, acordos e decisões, o diálogo busca a reflexão conjunta e a observação cooperativa da experiência, exercitando novos modos de vista e criando significados em conjunto. Nesse sentido, o diálogo não incorpora a fragmentação e a supersimplificação dos fatos, indo de acordo com as idéias holísticas de Bohm (cada parte do universo retrata o todo). Mariotti (2003) aborda as danosas consequiências da fragmentação dos fatos e da lógica comum do "concordo-discordo". Ao permear o diálogo, a palavra liga e não separa, aglutina e não fragmenta, forma "redes de conversação".

O diálogo e a discussão são formas complementares de conversação, e cada um tem sua função dependendo do contexto. Há situações em que a discussão (modelo mental fragmentador) é útil na resolução de questões práticas da vida e fenômenos objetivos. Em outras situações, necessitamos de pensamentos abrangentes/globais, considerando sentimentos, emoções e intuições, e compreendendo a transição entre o todo e as partes (Mariotti, 2003).

A importância do diálogo é refletida nas questões relativas à gestão negociada. Desequilíbrio do nível de informação entre os decisores fragmenta o coletivo decisório e quebra as "redes de conversação", podendo levar a desequilíbrios de poder, de participação 
e de decisão. A democracia local pode ser, desse modo, contraditória em razão de sua incapacidade em suplantar os particularismos em detrimento do beneficio comum. Sem a presença do diálogo no momento certo, os representantes mais capacitados e organizados tendem a dominar as decisões. $\mathrm{O}$ consenso não é necessariamente democrático.

O diálogo é, naturalmente, um processo potencialmente útil na integração de conhecimentos científicos e vivenciais, mas alguns princípios podem facilitar sua inserção em um processo de gestão como é o caso da informação, da flexibilidade, da abordagem sistêmica e da visão holística. Segundo Barnard (citado por Hampton, 1991), "a arte perfeita da decisão... consiste em não decidir precipitadamente e em não tomar decisões ineficientes". O processo decisório participativo está diretamente subordinado aos princípios sistêmicos necessários em qualquer processo de gestão. Todo modelo sistêmico se organiza pela correspondência de um sistema operacional com um sistema decisório, por meio de um sistema informacional. Nessa perspectiva, há uma estreita inter-relação entre atores, fatores e fluxos ambientais. A informação in-forma a organização, enquanto a organização organiza a informação que a forma. À medida que a organização organiza/acumula informações, ocorre a "memorização" da organização, ou seja, a criação de uma memória "coletiva" que se desenvolve de acordo com os inputs do meio. Nesse caso, a informação é, para a organização, o que a matéria é para a energia (Le Moigne, 1977).

Uma das teorias potencialmente úteis à gestão participativa da água no Brasil é a TSG - Teoria do Sistema Geral (Le Moigne, 1977), a qual se contrapõe aos princípios racionalistas e deterministas do método cartesiano (proposto por Descartes em 1637). Também não defende o rigor da ciência cognitiva quanto à sub-valorização dos fatores afetivos, históricos, culturais e o contexto do comportamento e do pensamento. Na TSG, um decisor é certamente influenciado por conhecimentos científicos, mas também por conhecimentos empíricos derivados de sua vivência. O preceito da Evidência de Descartes ("o verdadeiro é o que pode ser provado"), deve ser complementado pelo preceito da Pertinência, pelo qual todo objeto ou fato se define com respeito às intenções implícitas ou explícitas do analista. Nesse caso, 
deve-se encarar algo como verdadeiro não apenas quando seja comprovado cientificamente, mas também segundo nossa inteligência perceptiva. No caso da gestão da água, os interesses e arranjos pessoais e coletivos integram o processo decisório participativo.

Em relação ao princípio do Reducionismo (análise dos fatos por meio de sua decomposição), a TSG defende que a fragmentação pode dificultar a busca das soluções e, nem sempre, a soma das partes resulta no todo. O todo pode ser mais do que a soma das partes e a parte é mais do que uma fração do todo. No caso da gestão da água, a visão sistêmica auxilia a compreensão da cadeia de fluxos e fenômenos da natureza, mas não permite a análise simultânea da sua complexidade (o todo). Adotando como exemplo o caso dos $\mathrm{CBHs}$, torna-se útil o princípio do Globalismo, segundo o qual, cada parte deve ser percebida como inserida, imersa, ativa no todo (no ambiente). O Globalismo envolve o princípio da abertura dos sistemas, ao contrário dos "sistemas fechados" do reducionismo.

O determinismo ou causalismo é outro princípio rejeitado pela TSG. Adotado por Descartes, mas proposto anteriormente por Kepler, Galileu e Newton, o determinismo se apóia na crença de um mundo com uma ordem baseada em leis de causa-efeito invariáveis. O ser racional é aquele que se comporta conforme as leis já conhecidas, ou crê que as leis existem desde sempre na natureza e cabe a ele identificá-las. No entanto, como defende a TSG, o homem pode ser racional sem ser determinista. As mesmas causas não levam às mesmas conseqüências, e as conseqüências têm significado e impactos diferentes para cada ser humano. Os meios estão ligados aos fins (resultados), e um meio pode não levar ao final esperado. O princípio da Racionalidade, na TSG, vem justamente enfocar o estudo das relações e compatibilidade entre meios e fins, em relação à finalidade do objeto estudado. A interpretação de um objeto se baseia em seu comportamento, e não em leis e estruturas.

Finalmente cabe destacar a contraposição do princípio cartesiano da exaustividade, segundo o qual o homem deve compreender detalhadamente um objeto a partir da análise de todas as suas partes e aspectos. Como visto, o Globalismo defende que o homem não é capaz de compreender a complexidade dos fatos a partir 
da sua fragmentação. Toda representação é parcial, devendo-se selecionar agregados de informações e excluir a ilusória objetividade de uma investigação integral. $\mathrm{O}$ enfoque de um objeto deve priorizar os aspectos de maior interesse (princípio da Agregação).

No caso dos CBHs, a gestão de fenômenos ambientais interligados insere-se em uma complexidade não mensurável. As águas existem em contextos distintos, integrados, sistêmicos e mutuamente condicionados. O desdobramento e o conhecimento total da complexidade ambiental não é uma tarefa ao alcance da humanidade, atualmente, fato agravado por obstáculos como a escassez de informações. Os decisores não têm como deixar de omitir certas dimensões do conhecimento na gestão da água, devendo selecionar e agregar as informações mais relevantes.

Tratando da complexidade, Edgar Morin (citado por Le Moigne, 1977) ilustra os contrapontos aos princípios cartesianos e deterministas: "Diferentemente de Descartes que falava de um princípio simples de verdade, ou seja, identificação da verdade por meio de idéias claras e distintas, e além, podia propor um discurso do método em algumas páginas, eu faço um discurso muito mais longo na busca de um método que não se revela por qualquer evidência inicial, devendo ser elaborado perante esforço e riscos. A missão deste método... é convidar cada um a pensar na complexidade".

\section{Conclusões: a integração de conhecimentos e valores como chave para a operacionalização da gestão participativa no Brasil}

O processo participativo de gestão da água envolve uma variedade e, portanto, uma complexidade ambiental incompatível com qualquer visão reducionista. A falta de uma abordagem adequada pode fazer com que a complexidade do ambiente se torne uma barreira ao processo decisório, levando a um controle dos decisores pelo sistema que os envolve (inversão do processo). Este fato pode indicar disfunções nos organismos decisórios, não pela complexidade ambiental em si, mas pela forma com que o organismo trata tal complexidade (Tab. 4). 


\section{Tabela 4 - Comparação entre os pensamentos linear e sistêmico}

\begin{tabular}{l|l}
\hline \multicolumn{1}{c|}{ Pensamento Linear } & \multicolumn{1}{c}{ Pensamento em Sistemas } \\
\hline Existe um problema. & Existe um problema. \\
\hline Ele tem uma causa única. & Ele está encaixado nas circunstâncias. \\
\hline Ele exige uma solução única. & Ele exige solução. \\
\hline $\begin{array}{l}\text { A solução pode ser avaliada em termos de } \\
\text { seu impacto sobre o problema. }\end{array}$ & $\begin{array}{l}\text { A solução terá outros efeitos além do impacto que } \\
\text { se pretende que tenha sobre o problema. }\end{array}$ \\
\hline A solução permanecerá. & É prudente tentar prever os resultados. \\
\hline- & $\begin{array}{l}\text { A solução pode ser avaliada, identificando -se o } \\
\text { conjunto de resultados esperados e inesperados. }\end{array}$ \\
\hline- & $\begin{array}{l}\text { A solução não permanecerá, uma vez que as } \\
\text { circunstâncias mudam. }\end{array}$ \\
\hline
\end{tabular}

Fonte: Hampton (1991).

A democratização do conhecimento é um dos pilares da governabilidade da água. $\mathrm{O}$ conhecimento científico é essencial ao processo de compreensão da realidade e de gestão da água, sem o qual a sociedade torna-se vulnerável à imprecisão e à deformação dos fatos. A prévia informação e sensibilização dos atores envolvidos contribui para o intercâmbio de conhecimentos no processo decisório.

Juntamente com a importância do conhecimento científico e dos indicadores para a gestão da água tem-se valorizado, cada vez mais no mundo, a idéia de aumento da eficácia da gestão da água, com a assimilação dos saberes locais. Somente o acesso à informação técnica não garante a mudança de idéias e comportamentos da sociedade e dos decisores nos CBHs. Apesar dos riscos inerentes aos valores subjetivos, vínculos sentimentais em relação ao meio ambiente e ao meio local, e a confiança no próprio poder de mudança são apontados como fatores essenciais à gestão participativa (Romano Filho, Sartini \& Ferreira, 2002).

No Brasil, assim como na França, os membros de CBHs com formação técnica não são, em geral, os atores locais. Os "experts" tendem a pertencer ao poder público estadual ou federal, ou ao setor dos grandes usuários da água. Muitas vezes, esses decisores possuem uma visão externa que lhes permite um referencial global da bacia hidrográfica, percebida como um território coerente e ideal para a gestão da água. De outro lado, o conhecimento local está potencialmente presente nos representantes da sociedade civil. Esses possuem vivências e percepções que lhes conferem uma visão interna da bacia, mas fortemente fragmentada pelas fronteiras administrativas e divisões de interesses. Na França, tem sido verificado que, quando 
há forte assimetria de conhecimento vivencial e técnico entre decisores, a organização tende à gestão "racional" (base técnica), e não ao apaziguamento de conflitos no processo (Salles \& Zellem, 1998). Predominam as discussões e debates, e não o diálogo para o fluxo de informações. Trabalhos têm demonstrado que a mobilização coletiva, na sociedade e nos CBHs, ocorre, em grande parte, em função de ajustes cognitivos (Magalhães Jr., 2003). Buscando um ponto de equilíbrio e conciliação de conhecimentos, os CBHs devem buscar a integração entre os conhecimentos científicos e vivenciais (Evidência $\mathrm{X}$ Pertinência).

A essência dos $\mathrm{CBHs}$ é a abertura à diversidade de vivências e idéias (diálogo), fato associado ao equilíbrio de poder decisório. $\mathrm{O}$ processo decisório é diretamente condicionado pelos valores, interesses e escolhas humanas que determinam as decisões. Esse condicionamento pode ser mais decisivo do que a existência ou a qualidade das informações, de estruturas metodológicas ou de um suporte tecnológico.

Apesar da importância do conhecimento local, a gestão participativa não pode prescindir da expertise, sob o risco de perder sua credibilidade. A comprovação dos fatos aumenta sua aceitação. A democratização do conhecimento científico deve ser adequadamente estruturada em dois eixos: a disponibilização de dados brutos que permitam a produção de informações e a capacitação para a avaliação crítica do conhecimento científico, e a adequação da difusão do conhecimento a fim de permitir, senão facilitar, sua compreensão pelos decisores. $\mathrm{O}$ enfoque dado, neste trabalho, aos conhecimentos e valores envolvidos na gestão participativa da água não deve esconder outros condicionantes do sucesso da operacionalização dos CBHs no Brasil, estruturados segundo três eixos principais: a base legal/institucional, fiscalização/licenciamento ambiental, e os planos e programas de planificação. A operacionalização desses eixos de ação está associada ao estabelecimento de prioridades e metas de gestão e de monitoramento, à integração de conhecimentos diversificados e sistemas de informações, e à democratização do conhecimento científico e vivencial entre os decisores em qualquer instância do SNGRH. Os CBHs funcionariam, portanto, como elos de uma cadeia sistêmica de 
indivíduos, instituições e informações, na qual um contínuo fluxo de idéias e conhecimentos facilitaria o processo decisório participativo.

\title{
Notas
}

1 A ciência é definida sinteticamente, por Herbert Spencer, como o conhecimento organizado (Williams, 1999).

2 Bohm usa a figura do holograma, um registro fotográfico dos padrões de interferência de ondas luminosas, refletidas por um objeto. O holograma não faz a correspondência exata entre a imagem e o objeto fotografado. Ele insere "a forma e a estrutura do objeto inteiro em cada parte do registro fotográfico". Por isto, cada parte contém informações do todo.

3 A palavra "diálogo" resulta da fusão das palavras gregas dia ("por meio de") e logos (razão, palavra, expressão, verbo).

4 Apesar de possuírem pontos em comum, a TSG (Teoria do Sistema Geral) deve ser distinguida da TGS (Teoria Geral dos Sistemas) de Bertallanfy (1975). O biólogo Bertallanfy pesquisou sistemas vivos e definiu um sistema ou organismo como constituído de partes mutuamente dependentes e processos mutuamente interativos. O todo depende das partes e as partes dependem do todo. Seus estudos abriram caminho para as teorias sobre interdependência. As teorias sobre famílias de sistemas extrapolaram as idéias de Bertallanfy ao propor que as famílias se auto-regulam, e que qualquer mudança em uma parte do sistema afeta todas as suas partes.

\begin{abstract}
The approval of the Water Law in Brazil (Law n ${ }^{\circ}$ 9.433/97) did not guarantee its operation, including the partaking management principle on the jurisdictions of basin organisms (comitês de bacias hidrográficas). This work approaches the importance of conjunct consideration of scientific and experimental knowledge, as well as the formation of a net information society, for the viability of the process. Aspects such as deciders training, systemic vision, subjectivity, values, perceptions, attitudes, ethics and dialog are some of the approached cognitive elements, which are considered strategic for the success of partaking management. The work aims to raise reflections about the role of knowledge and about the relevance of the integration of individual qualities on the search for efficient deciding processes. The research was made as part of the doctorate process at the Centro de Desenvolvimento Sustentável/UnB.
\end{abstract}


Key-words: indicators, hydrographic basin comitees, water management

Résumé: L'aprobation de la Loi sur L'eau (Loi 9.433/97) n'a pas garanti sa mise en oeuvre, y compris le principe de la gestion participative de l'eau au niveau des organismes de bassin (Comitês de Bacia Hidrográfica). La recherche concerne l'importance de la prise em compte d'informations cientifiques ou viventielles, ainsi que la formation d'une société d'information en réseau pour l'aide au processus participatif. La capacitation des décideurs, la vision systèmique, des valeurs, des perceptions, des attitudes, l'étique et le dialogue sont certains des élements cognitifs abordés et pris en tant que stratégiques pour la gestion participative. La recherche a l'intention de susciter des réflexions a propos du rôle des informations et sur la relevance de l'intégration des qualités individuelles dans le processus de décision participatif. L'article résulte du processus de doctorat réalizé au Centro de Desenvolvimento Sustentável/Universidade de Brasilia.

Mots-clés: indicateurs, comités de basin hidrographique, gestion de l'eau.

\section{Referências bibliográficas}

BELLIA, V. Introdução à Economia do Meio Ambiente. Brasília: IBAMA, 1996. $262 \mathrm{p}$.

BERTALLANFY, L. Teoria geral dos sistemas. Petrópolis: Vozes, 1975. 351 p.

BOHM, D. A totalidade e a ordem implicada: uma nova percepção da realidade. Trad. de Mauro de Campos Silva. São Paulo: Cultrix, 1992. 292 p.

BOHM, D. On dialogue. Londres: Routledge, 1998; citado em: MARIOTTI, H. Diálogo: um método de reflexão conjunta e observação compartilhada da experiência. Pluriverso - Pensamento Sistêmico, Política e Cultura. <www.pluriversu.org>. Disponível em: <http:// www.geocities.com/pluriversu/dialogo.html >. Acessado em: 6 maio 2003.

BRYANT, R. L., BAILEY, S. Third world political Ecology. London: Clays,1997. p. 130-183. 
BURSZTYN, M. A. A. Gestão ambiental: instrumentos e práticas. Brasília: MMA-IBAMA, 1994, p. 13-33.

BURSZTYN, M. A. A.; BENAKOUCHE, R.; BURSZTYN, M. Os instrumentos econômicos e a política ambiental. Brasília, dez. 1994. 25 p. Apostila.

CASTELLS, M. A sociedade em rede. São Paulo: Paz e Terra, 1999. v.1.

CORREIA, F. N. (Coord.). Water 21: towards sustainable european water management, appraisal of current water policies and required action, final report. Lisboa: Instituto Superior Técnico, 1999. 27 p.

COSGROVE, W. J.; RIJSBERMAN, F. R. World water vision: making water everybody's business. London: Earthscan Publications, World Water Council, 2000. $70 \mathrm{p}$.

DIEGUES, A. C. S. O mito moderno da natureza intocada. São Paulo: Hucitec, 1996.

DRIVER, M. J.; BROUSSEAU, K. R.; HUNSAKER, P. L. The dynamic decision maker. San Francisco: Jossey-Bass, 1993. p. 1-18.

DUBOSC, A. La participation du public dans le processus de décision liés à l'eau. Paris: Agence de l'Eau Seine-Normandie, 2001. 24 p.

GARDNER, H. A nova ciência da mente. Trad. Cláudia M. Caon. São Paulo: EDUSP, 1995.

GLEASON, G. Theory of racional action. Mexico: Universisy of New Mexico. Disponível em: <http://www.unm.edu/ igleason/notes/ topic2.html>. Acessado em: 06 maio 2003.

GOLDBLATT, D. Teoria social e ambiente. Lisboa: Perspectivas Sociológicas, 1996. p. 17-34 e 271-289.

HAKEN H.; PORTUGALI, J. Synergetics, inter-representation networks and cognitive maps. In: PORTUGALI, J. (Ed.). The construction of cognitive maps. Dordrecht: Kluwer Academic Publishers, 1996. p. 45-67.

HAMPTON, D. R. Administração contemporânea. São Paulo: Mc GrawHill, 1991, p. 230-255.

HERCULANO, S. C. A qualidade de vida e seus indicadores. Ambiente e Sociedade, Campinas, v. 1, n. 2, p. 77-99, 1998.

HORN, R. V. Statistical indicators: for the economic \& social sciences. Cambridge: Cambridge University Press, 1993. 227 p. 
IFEN (Institut Français de l'Environnement). Les indicateurs de développement durable: méthodes et perspectives. Orléans: Corbet, Études et Travaux, 1999. 145 p.

LAMBERT, R. Géographie du cycle de l'eau. Toulouse: Presses Universitaires du Mirail, Université de Toulouse-Le Mirail, 1996, 439 p.

LE MOIGNE, J-L. La théorie du système général: théorie de la modélisation. 3 ed. Paris: Presses Universitaires de France, 1977. 330 p.

LOVELOCK, J. E. Gaia: A new look at life on earth. Oxford: Oxford University Press, 1979. p. 1-12. In: NELISSEN, N.; STRAATEN, J. V. D.; KLINTERS, L. (Eds.). Classics in environmental studies: an overview of classic texts in environmental studies. Utrecht: International Books, 1997. p. 127-142.

MAGALHÃES Jr., A. P. Os indicadores como instrumentos de apoio à consolidação da gestão participativa da água no Brasil: realidade e perspectivas no contexto dos comitês de bacia hidrográfica. 2003. Tese (Doutorado) - Centro de Desenvolvimento Sustentável/UnB,

MANTOVANI, M.; BARRETO, S. R. A atuação das organizações nãogovernamentais no sigrh, seu fortalecimento e a nova postura em face da lei 9.790/99 - o marco regulatório do Terceiro Setor. In: THAME, A. C. M. (Org.). Comitês de bacias hidrográficas: uma revolução conceitual. São Paulo: IQUAL Editora, 2002. p. 89-96.

MARIOTTI, H. Diálogo: um método de reflexão conjunta e observação compartilhada da experiência. Pluriverso, Pensamento Sistêmico, Política e Cultura. <www.pluriversu.org>. Disponível em: <http:// www.geocities.com/pluriversu/dialogo.html $>$. Acessado em: 6 maio 2003.

MENARD, C. Enjeux d'eau: la dimension institutionnelle. Tiers Monde, Paris, v. 42 , p. $259-274,2001$.

MEUBLAT, G. La rénovation des politiques de l'eau dans les pays du sud. Tiers Monde, Paris, v. 42, p. 249-257, 2001.

MITCHELL, B. Geography and resources analysis. London: Longman, 1979. p. 118-143.

MOLES, A. A. Existe uma qualidade da vida cotidiana? In: WITKOWSKI, N. (Coord.). Ciência e Tecnologia. Tradução de Roberto Leal Ferreira. São Paulo: Ensaio, 1995. p. 35-37. 
OLIVRY, Didier. Participation des communautés locales et groupes d'Intérêts a la planification et la gestion des projets hydrauliques. 1985. Thèse (Doctorat) - Université Paris XII - Val de Marne.

PEÑA, H.; SOLANES, M. La gobernabilidad del agua en las Américas: una tarea inconclusa. México, 2002. 35 p. Documento preparatório para el Foro del Agua para las Américas en el Siglo XXI.

PORTUGALI, J. Inter-representation networks and cognitive maps. In: PORTUGALI, J. (ed.). The construction of cognitive maps. Dordrecht: Kluwer Academic Publishers, 1996. p. 11-43.

. Self-organized inter-representation networks: a proposal for the Varenius Workshop on Cognitive Models of Dynamic Phenomena and their Representation. (s.1.). 1998. Disponível em: <http:// www2.sis.pitt.edu/ cogmap/ncgia/portugali.html>. Acessado em: 6 maio 2003.

. The seven basic propositions of SIRN (Synergetic InterRepresentation Networks). Nonlinear Phenomena in Complex Systems, v. 5, n. 4, p. 428-444. 2002. Disponível em: <http://www.jnpcs.org>. Acessado em: 7 maio 2003.

REID, L. The sociology of nature. Harmondsworh: Penguin Books, 1962. p. 13-26. In: NELISSEN, N.; STRAATEN, J. V. D.; KLINTERS, L. (Eds.). Classics in environmental studies: an overview of classic texts in environmental studies. Utrecht: International Books, 1997. p. 57-67,

ROMANO FILHO, D.; SARTINI, P.; FERREIRA, M. M. Gente cuidando das águas. Belo Horizonte: Mazza Edições, Instituto de Resultados em Gestão Social, 2002.

RNG (ROYAL NETHERLANDS GOVERNMENT). Sector Wide Approach. Disponível em: <http://www.holland.com.ye/swap.htm>. Acessado em: 7 maio 2003.

SALLES, D.; ZELEM, M-C. La négociation des contrats de rivière. Pour, Vers une gestion concertée de l'eau, Paris, n. 157, p. 29-38, 1998.

SZILAGYI Jr, A. D. Management and performance. 2. ed. Glenview: Scott, Foresman, 1984. p. 210-234.

TRACY, D. Dez passos para o empowerment: um guia sensato para a gestão de pessoas. Rio de Janeiro: Campus, 1994. p. 1-165. 
VARESE, F. Altruism and the theory of rational choice: an empirical exploration in collaboration with Meir Yaish. Disponível em: <http:/ /www.nyu.edu/gsas/dept/politics/seminars/varese_altruism.pdf >. Nov. 2001. Acessado em: 6 maio 2003.

WILLIAMS, H. S. A History of Science. Champaign Project Gutemberg. Disponível em: <http://promo.net/pg>. Acessado em: 13 nov. 1999.

WORLD BANK. Comprehensive development framework. Disponível em: <http://www.worldbank.org>. Acessado em: 6 maio 2003. 